G. Boner • M. E. Cooper - K. McCarroll •

B. M. Brenner - D. de Zeeuw • P. R. Kowey •

S. Shahinfar · T. Dickson - R. S. Crow $\cdot$ H.-H. Parving •

RENAAL Investigators

\title{
Adverse effects of left ventricular hypertrophy in the reduction of endpoints in NIDDM with the angiotensin II antagonist losartan (RENAAL) study
}

Received: 10 February 2005 / Accepted: 1 May 2005 / Published online: 5 August 2005

(C) Springer-Verlag 2005

\begin{abstract}
Aims/hypothesis: We explored the impact of baseline left ventricular hypertrophy (LVH) and losartan treatment on renal and cardiovascular (CV) events in 1,513
\end{abstract}

G. Boner $(\bowtie)$

Department of Internal Medicine, Sackler Faculty of Medicine, University of Tel Aviv,

Ramat Aviv,

Tel Aviv, Israel

e-mail: gboner1@barak-online.net

Tel.: +972-9-8666382

Fax: +972-9-8664561

\section{E. Cooper}

Danielle Alberti Memorial Centre for Diabetes Complications,

Vascular Division, Wynn Domain,

Baker Medical Research Institute,

Melbourne, Victoria, Australia

K. McCarroll · S. Shahinfar · T. Dickson

Merck Research Laboratories,

Blue Bell, PA, USA

B. M. Brenner

Renal Division, Brigham and Women's Hospital,

Boston, MA, USA

D. de Zeeuw

Department of Clinical Pharmacology,

University Medical Center,

Groningen, The Netherlands

P. R. Kowey

Division of Cardiovascular Diseases,

Jefferson Medical College,

Philadelphia, PA, USA

R. S. Crow

Division of Epidemiology, University of Minnesota,

Minneapolis, MN, USA

H.-H. Parving

Steno Diabetes Center,

Gentofte, Denmark

H.-H. Parving

Faculty of Health Science, University of Aarhus,

Aarhus, Denmark patients from the Reduction of Endpoints in NIDDM with the Angiotensin II Antagonist Losartan (RENAAL) trial, which studied the effects of losartan on the progression of renal disease and/or death in patients with type 2 diabetes and nephropathy. Materials and methods: LVH was assessed using ECG criteria (Cornell product and/or Sokolow-Lyon voltage). The risk of renal or CV events was determined by a proportional hazards model fit with treatment allocation and presence of $\mathrm{LVH}$. Covariates at baseline included age, sex, systolic BP, mean arterial pressure, pulse, proteinuria, serum creatinine, albumin and haemoglobin. Results: A total of 187 subjects $(12 \%)$ had LVH at baseline. Treatment with losartan resulted in a significant decrease in the Cornell product $(-6.2 \%)$ and Sokolow-Lyon voltage $(-6.3 \%)$. LVH was shown to be significantly associated with the primary endpoint, which was a composite of doubling of serum creatinine (DSCR), endstage renal disease (ESRD) or death (hazard ratio [HR] $=$ $1.44, p=0.011$ ), as well as with the composite renal endpoint of DSCR/ESRD $(\mathrm{HR}=1.42, p=0.031)$ and $\mathrm{CV}$ events $(\mathrm{HR}=1.68, p=0.001)$. Losartan treatment of patients with $\mathrm{LVH}$ decreased the $\mathrm{CV}$ as well as renal risk to a level similar to that of patients without LVH. Conclusions/ interpretation: In patients with type 2 diabetes and nephropathy, LVH is associated with significantly increased risk of $\mathrm{CV}$ events and the progression of kidney disease. Importantly, in patients with LVH, losartan reduced the $\mathrm{CV}$ as well as the renal risk to a level similar to that seen in subjects without LVH.

Keywords Cardiovascular events · Diabetic nephropathy · Left ventricular hypertrophy · Losartan · Progression of renal disease - Type 2 diabetes

Abbreviations CV: cardiovascular - DSCR: doubling of serum creatinine - ESRD: endstage renal disease $\cdot$ HR: hazard ratio - LIFE: Losartan Intervention for Endpoint Reduction in Hypertension study - LVH: left ventricular hypertrophy · RENAAL: Reduction of Endpoints in NIDDM with the Angiotensin II Antagonist Losartan trial 


\section{Introduction}

Left ventricular hypertrophy (LVH) has consistently been linked to the increased prevalence of cardiovascular (CV) events in a variety of patient populations [1-4]. In addition, the risk of death or non-fatal complications is increased two- to four-fold in the presence of LVH even when age, sex and other risk factors are taken into account [1-5]. Furthermore, there is evidence that this risk may be enhanced by the presence of diabetes mellitus [3, 6-10]. Patients with impaired renal function are also at high risk of $\mathrm{CV}$ events and this risk is further increased in patients with diabetic renal disease [11]. While diabetic nephropathy has been linked to CV events [12], the role of LVH as an additional $\mathrm{CV}$ risk factor has not been determined in this patient population. Although LVH is common in patients with impaired renal function, no studies to date have examined the impact of LVH on renal disease progression in patients without overt CV disease [13].

The Reduction of Endpoints in NIDDM with the Angiotensin II Antagonist Losartan (RENAAL) trial was designed primarily to study the effects of losartan on progression of renal disease and/or death in patients with type 2 diabetes and nephropathy. The major finding was that losartan had a significant beneficial effect on renal endpoints and was associated with a significant reduction in hospitalisations for heart failure, but not for $\mathrm{CV}$ events [14]. The present analysis investigates the impact of LVH (based on previously validated ECG criteria) [15] on the renal and $\mathrm{CV}$ outcomes in these patients. In addition, the effects of losartan treatment on $\mathrm{LVH}$, renal and $\mathrm{CV}$ endpoints in patients with or without LVH were also determined.

\section{Subjects, materials and methods}

The study design and inclusion/exclusion criteria for RENAAL have been reported in detail previously $[14,16]$. Briefly, RENAAL was a multinational, double-blind, randomised, placebo-controlled study in 1,513 patients with type 2 diabetes and proven nephropathy in 250 centres in 28 countries. The investigational review board at each of the centres approved the study, and all patients gave written informed consent. An independent Endpoints Committee whose members were unaware of the patients' treatment assignments reviewed the data to determine which patients had reached the endpoints. In addition all renal and CV events, including death and its cause, were adjudicated. Patients were stratified according to baseline urinary albumin : creatinine ratio $(<226.2 \mathrm{mg} / \mathrm{mmol}[<2,000 \mathrm{mg} / \mathrm{g}]$ or $>226.2 \mathrm{mg} / \mathrm{mmol}[>2,000 \mathrm{mg} / \mathrm{g}])$, and randomised to either losartan-based therapy $(50 \mathrm{mg}$ titrated to $100 \mathrm{mg}$ once daily) or placebo-based therapy. Other antihypertensive medications, except for ACE inhibitors and angiotensin receptor blockers, could be added if the trough sitting BP did not reach the goal of $<140 / 90 \mathrm{mmHg}$. Patients were followed for an average duration of 3.4 years.
Patient population

The study population included both men and women aged between 31 and 70 years. The patients were diagnosed with type 2 diabetes and clinical nephropathy (albuminuria $>300 \mathrm{mg} / \mathrm{g}$ creatinine from a first morning specimen, or proteinuria of $>0.5 \mathrm{~g} /$ day and serum creatinine of 115 $265 \mu \mathrm{mol} / 1(1.3-3.0 \mathrm{mg} / \mathrm{dl})$ with or without hypertension. Patients with a history of a CV event or intervention 1-12 months prior to study enrolment were excluded.

\section{Endpoints}

The primary endpoint of the RENAAL study was a composite of doubling of serum creatinine (DSCR), endstage renal disease (ESRD) or death. In addition, the pre-specified renal composite endpoint of DSCR/ESRD was also included. The secondary CV endpoint comprised myocardial infarction, stroke, hospitalisation for heart failure or unstable angina, coronary or peripheral revascularisation or death due to $\mathrm{CV}$ causes.

\section{Detection of LVH}

ECGs were obtained at baseline and annually from all subjects using a standard supine 12-lead ECG protocol and a standardised method for electrode placement. ECGs were then assessed centrally, using the Cornell product and Sokolow-Lyon voltage criteria, which had been used in the LIFE (Losartan Intervention for Endpoint Reduction in Hypertension) study and validated [17-21] in a large number of patients. Furthermore, the Cornell product criteria have been shown to be more sensitive in diagnosing LVH in obese patients and were thus considered to be more robust in assessing the presence or absence of LVH in this study [22].

The Minnesota Code rules [23] were used for visual measurement of amplitude and duration of the QRS wave, each measurement being repeated independently. The following criteria for LVH were used: Cornell product greater than $2,440 \mathrm{~mm} \times \mathrm{ms}[19,24]$ or Sokolow-Lyon voltage greater that $38 \mathrm{~mm}$ [18].

The Cornell product was calculated using an adjustment for sex as: Cornell product $=(\mathrm{QRS}$ duration $[\mathrm{ms}]) \times(R$ in $\mathrm{AVL}+S$ in $V_{3}[\mathrm{~mm}]+k$ ), where $k=0$ for men and $k=6$ for women.

The Sokolow-Lyon voltage was calculated as: Sokolow-Lyon voltage $=S$ in $V_{1}+R$ in $V_{5}$ or $V_{6}$.

\section{Statistical analysis}

Treatment groups, defined according to intent-to-treat, were compared with respect to the change in the Cornell product and Sokolow-Lyon voltage from baseline to the end of follow-up (either study end or patient drop-out) 
using a Wilcoxon analysis. Baseline characteristics were compared using chi-square tests for categorical variables and a Wilcoxon test for continuous variables. The effect of LVH on outcomes was analysed by calculating KaplanMeier estimates for time-to-event data.

To determine the risk of renal or $\mathrm{CV}$ events the total cohort was analysed using a proportional hazards model that was fitted with treatment allocation and presence of LVH. The following baseline covariates were included in the model: age, sex, systolic BP, mean arterial pressure, pulse, proteinuria, serum creatinine, albumin and haemoglobin. In addition, mean arterial pressure at the time of the specific endpoint was also included in the model (not a baseline endpoint). A model-fitting strategy was used that consisted of the following steps: (1) test each covariate independently in a model with LVH and treatment; (2) include all potentially significant covariates $(p<0.10)$ in a model with LVH and treatment; and (3) remove those covariates that were non-significant $(p>0.05)$.

Thus, the final model for each endpoint contained LVH and treatment and those covariates that were statistically significant at the 0.05 level.

\section{Results}

\section{Baseline characteristics}

Of the 1,513 patients randomised to treatment, $187(12 \%)$ fulfilled the criteria for LVH at baseline, whereas 1,240 patients did not have LVH and 86 patients with insufficient data were excluded. Of the patients diagnosed as having LVH, $73.8 \%$ had an elevated Cornell product, $33.2 \%$ an increased Sokolow-Lyon voltage and $6.0 \%$ an increase in both criteria. Nine per cent of the patients with an elevated Cornell product had an increased Sokolow-Lyon voltage as well, while $81 \%$ had a normal Sokolow-Lyon voltage and in $10 \%$ there were insufficient data. Of the patients with an increased Sokolow-Lyon voltage, $21 \%$ had an elevated Cornell product and in $79 \%$ the product was not elevated. Table 1 summarises and compares the baseline characteristics of those with or without LVH. The patients with LVH were characterised by: female sex, higher systolic BP, higher mean arterial pressure, a greater percentage of patients receiving antihypertensive therapy, higher heart rate, increased urinary albumin: creatinine ratio, increased glomerular filtration rate and a history of slightly more myocardial infarction. There were no differences in serum lipid values, glycaemic control, use of insulin and smoking between the two groups. Serum creatinine levels were higher in the placebo group (mean \pm SD $176.8 \pm 44.2$ vs $159.1 \pm$ $35.4 \mu \mathrm{mol} / 1, p=0.004$ ) and there was a higher percentage of smokers in the losartan group ( 27 vs $15 \%, p=0.042$ ) in patients with LVH. In the patients without LVH there was a slightly higher BMI in the losartan group (mean \pm SD $30.1 \pm$ 6.5 vs $29.5 \pm 6.3, p=0.048)$.
Table 1 Baseline characteristics by presence or absence of LVH

\begin{tabular}{|c|c|c|c|}
\hline Characteristic & $\begin{array}{l}\text { Without LVH } \\
(n=1240)\end{array}$ & $\begin{array}{l}\text { With LVH } \\
(n=187)\end{array}$ & $p$ \\
\hline Age (years, mean \pm SD) & $60 \pm 7.5$ & $61 \pm 7.2$ & 0.038 \\
\hline \multicolumn{4}{|l|}{$\operatorname{Sex}(n)$} \\
\hline Female & $447(36 \%)$ & $88(47 \%)$ & \multirow[t]{2}{*}{0.004} \\
\hline Male & $793(64 \%)$ & $99(53 \%)$ & \\
\hline \multicolumn{4}{|l|}{ Race } \\
\hline Asian & $205(17 \%)$ & $36(19 \%)$ & \\
\hline Black & $182(15 \%)$ & $34(18 \%)$ & \\
\hline Hispanic & $228(18 \%)$ & $34(18 \%)$ & \\
\hline White & $608(49 \%)$ & $82(44 \%)$ & \\
\hline Other & $17(1 \%)$ & $1(1 \%)$ & \\
\hline BMI (mean \pm SD) & $29.8 \pm 6.4$ & $29.1 \pm 5.9$ & 0.282 \\
\hline \multicolumn{4}{|l|}{$\mathrm{BP}(\mathrm{mmHg}$, mean $\pm \mathrm{SD})$} \\
\hline Systolic & $151.7 \pm 19.4$ & $159.1 \pm 17.7$ & $<0.001$ \\
\hline Diastolic & $82.3 \pm 10.4$ & $83.4 \pm 10.7$ & 0.166 \\
\hline Mean arterial & $105.4 \pm 11.2$ & $108.7 \pm 11.2$ & $<0.001$ \\
\hline Heart rate $($ mean \pm SD) & $69.4 \pm 17.9$ & $75.7 \pm 15.8$ & $<0.001$ \\
\hline \multicolumn{4}{|l|}{$\begin{array}{l}\text { Laboratory variables } \\
(\text { mean } \pm \mathrm{SD})\end{array}$} \\
\hline Creatinine $(\mu \mathrm{mol} / \mathrm{l})$ & $164.4 \pm 42.3$ & $170.5 \pm 45.2$ & 0.068 \\
\hline Total cholesterol (mmol/l) & $5.88 \pm 1.39$ & $6.09 \pm 1.58$ & 0.144 \\
\hline LDL-cholesterol (mmol/l) & $3.66 \pm 1.16$ & $3.81 \pm 1.28$ & 0.208 \\
\hline HDL-cholesterol (mmol/l) & $1.16 \pm 0.9$ & $1.16 \pm 0.39$ & 0.861 \\
\hline Triglycerides $(\mathrm{mmol} / \mathrm{l})$ & $2.47 \pm 2.21$ & $2.59 \pm 2.03$ & 0.589 \\
\hline Haemoglobin $(\mathrm{g} / \mathrm{l})$ & $124.8 \pm 18.4$ & $125.1 \pm 17.5$ & 0.915 \\
\hline $\mathrm{HbA}_{1} \mathrm{c}(\%)$ & $8.5 \pm 1.6$ & $8.4 \pm 1.6$ & 0.394 \\
\hline Serum uric acid $(\mu \mathrm{mol} / 1)$ & $398.5 \pm 101.1$ & $404.5 \pm 89.2$ & 0.421 \\
\hline $\begin{array}{l}\text { Urinary albumin: creatinine } \\
\text { ratio }(\mathrm{mg} / \mathrm{mmol})\end{array}$ & 135.75 & 176.3 & 0.009 \\
\hline Insulin use $(\%)$ & $751(61)$ & $109(58)$ & 0.553 \\
\hline Smokers $(\%)$ & $223(18)$ & $39(21)$ & 0.355 \\
\hline Antihypertensive use (\%) & $1,154(93)$ & $182(97)$ & 0.026 \\
\hline $\begin{array}{l}\text { Prior myocardial } \\
\text { infarction }(\%)\end{array}$ & $143(12)$ & $380(20)$ & $<0.001$ \\
\hline
\end{tabular}

\section{Reduction of LVH}

The Cornell product decreased significantly more in the losartan group $(1,432.8 \pm 61.3$ to $1,344.2 \pm 802.5)$ than in the placebo group $(1,482.3 \pm 771.6$ to $1,478 \pm 883.9)(p=0.007)$. The respective values for Sokolow-Lyon voltage were $22.3 \pm 8.2$ to $20.8 \pm 8.6$ and $22.9 \pm 8.0$ to $22.8 \pm 8.5$, the decrease being greater in the losartan group $(p<0.001)$. In patients with LVH, losartan was also associated with a greater decrease in Cornell product (losartan-12.5\% vs placebo-6.2\%) and Sokolow-Lyon voltage (losartan$16.6 \%$ vs placebo- $11.7 \%$ ), an effect that was also observed in patients without LVH.

All four groups showed a significant decrease in both systolic and diastolic BP from baseline measurement to last measurement (patients with LVH receiving losartan-10.3/ $8.1 \mathrm{mmHg}$, with $\mathrm{LVH}$ receiving placebo-13.4/7.8 $\mathrm{mmHg}$, 
Table 2 Baseline risk factors for renal and cardiovascular events

Age age per 10 year increase, Albumin serum albumin per unit decrease, $C V$ events myocardial infarction, stroke, hospitalisation for heart failure or unstable angina, coronary or peripheral revascularisation or death due to cardiovascular causes, $D S C R /$ $E S R D$ doubling of serum creatinine or endstage renal disease, $H b g$ blood haemoglobin per unit decrease, Losartan treatment with losartan vs placebo, $L V H$ left ventricular hypertrophy, Primary DSCR/ESRD or death, $\mathrm{SCr}$ serum creatinine per unit increase, $U A C r$ urinary albumin/ creatinine per $500 \mathrm{mg} / \mathrm{g}$ increase

\begin{tabular}{llrccc}
\hline Endpoint & Variable & \multicolumn{1}{c}{$p$} & Hazard ratio & Lower 95\% CI & Upper 95\% CI \\
\hline Primary & LVH & 0.001 & 1.41 & 1.15 & 1.74 \\
& Losartan & $<0.001$ & 0.74 & 0.63 & 0.87 \\
& SCr & $<0.001$ & 1.94 & 1.65 & 2.28 \\
& UACr & $<0.001$ & 1.14 & 1.11 & 1.17 \\
& Albumin & $<0.001$ & 1.85 & 1.46 & 2.35 \\
DSCR/ESRD & Hbg & 0.002 & 1.08 & 1.03 & 1.13 \\
& LVH & 0.007 & 1.40 & 1.10 & 1.79 \\
& Losartan & $<0.001$ & 0.69 & 0.57 & 0.84 \\
& SCr & $<0.001$ & 2.13 & 1.76 & 1.21 \\
& UACr & $<0.001$ & 1.17 & 1.14 & 2.52 \\
& Albumin & $<0.001$ & 1.9 & 1.44 & 1.19 \\
& Hbg & $<0.001$ & 1.12 & 1.06 & 0.98 \\
& Age & 0.019 & 0.86 & 0.077 & 1.78 \\
CV events & LVH & 0.006 & 1.4 & 1.10 & 1.08 \\
& Losartan & 0.256 & 0.90 & 0.75 & 1.51 \\
& SCr & 0.012 & 1.26 & 1.05 & 1.10 \\
& UACr & $<0.001$ & 1.07 & 1.05 & 1.56 \\
\hline
\end{tabular}

no $\mathrm{LVH}$ receiving losartan $-9 / 6.1 \mathrm{mmHg}$, and no $\mathrm{LVH}$ receiving placebo-6.0/4.8 $\mathrm{mmHg}$ ). Patients with LVH had significantly higher baseline BP values compared with patients who did not have LVH (Table 1). In patients with LVH the reduction in systolic BP over the course of the study was greater in the placebo-based therapy patients than the losartan-based therapy patients (losartan-10.3 \pm $20.6 \mathrm{mmHg}$ vs placebo $-13.4 \pm 21.0 \mathrm{mmHg}, p<0.05$ ).

\section{Risk associated with LVH}

Multivariate analysis of the total cohort demonstrated that $\mathrm{LVH}$ at baseline was significantly associated with an in- creased risk for the primary composite endpoint (Table 2). Of the 187 patients with LVH, 114 (61\%) experienced the primary endpoint compared with $568(46 \%)$ of the 1,240 patients without LVH (hazard ratio $[\mathrm{HR}]=1.41, p=0.001$ ). Consistent with prior findings from the RENAAL study, elevated serum creatinine, increased proteinuria, reduced serum albumin and decreased haemoglobin were also strong positive predictors of the primary composite endpoint. LVH also increased the risk of the composite renal endpoint of DSCR/ESRD and the risk of a CV event (Table 2). In addition, LVH was associated with an increased risk for DSCR $(\mathrm{HR}=1.38, p=0.03)$.

Table 3 Risk associated with LVH and the effect of losartan-based therapy on this risk

\begin{tabular}{|c|c|c|c|c|}
\hline \multirow[t]{2}{*}{ Risk } & \multicolumn{2}{|l|}{ Without LVH } & \multicolumn{2}{|l|}{ With LVH } \\
\hline & Placebo $(n=623)$ & Losartan $(n=617)$ & Placebo $(n=99)$ & Losartan $(n=88)$ \\
\hline \multicolumn{5}{|l|}{ Primary } \\
\hline $\mathrm{HR}(95 \% \mathrm{CI})$ & 1.00 & $0.75(0.63-0.89)$ & $1.44(1.09-1.89)$ & $1.04(0.76-1.42)$ \\
\hline$p$ & & 0.001 & 0.011 & 0.813 \\
\hline $\mathrm{HR}(95 \% \mathrm{CI})$ & 1.00 & $0.70(0.57-0.86)$ & $1.42(1.03-1.97)$ & $0.95(0.66-1.39)$ \\
\hline$p$ & & $<0.001$ & 0.031 & 0.805 \\
\hline \multicolumn{5}{|l|}{$\mathrm{CV}$ events } \\
\hline Number of events & $203(33 \%)$ & $199(32 \%)$ & $50(51 \%)$ & $32(36 \%)$ \\
\hline $\operatorname{HR}(95 \% \mathrm{CI})$ & 1.00 & $0.97(0.79-1.17)$ & $1.68(1.23-2.30)$ & $1.07(0.74-1.56)$ \\
\hline
\end{tabular}

Placebo without LVH is the reference group against which the other three groups are compared. Comparisons are made using a proportional hazards model adjusting for covariates such as age, proteinuria, albumin, haemoglobin and serum creatinine

$C V$ events myocardial infarction, stroke, hospitalisation for heart failure or unstable angina, coronary or peripheral revascularisation or death due to cardiovascular causes, DSCR/ESRD doubling of serum creatinine or endstage renal disease, $L V H$ left ventricular hypertrophy,

Primary doubling of serum creatinine, end-stage renal disease or death 


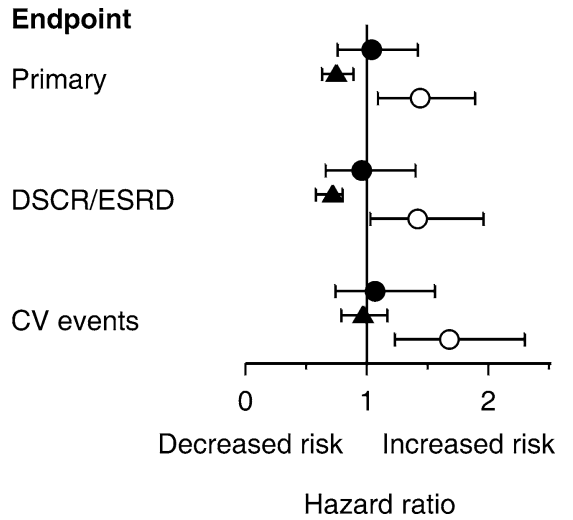

Fig. 1 Hazards ratios and 95\% CIs shown as box and whisker plots for the primary composite endpoint of DSCR, ESRD or death; the renal composite endpoint of DSCR/ESRD; and the CV morbidity and mortality composite endpoint. Comparisons are as follows: subjects with LVH and losartan treatment vs those without LVH and receiving placebo (closed circles); subjects without LVH receiving losartan or placebo (closed triangles); placebo-treated subjects with LVH vs those without LVH (open circles). A hazard ratio of less than 1 in each pair indicates a beneficial effect of the first over the second group, whereas a ratio greater than 1 indicates a deleterious effect of the first over the second group

\section{Interaction of treatment and LVH on renal outcomes}

Table 3 summarises the risk associated with LVH by treatment group. Patients without LVH on placebo-based therapy were used as the comparison group $(\mathrm{HR}=1)$. $\mathrm{Pa}$ tients with LVH at baseline, receiving placebo, were at highest risk for all endpoints (Table 3 and Fig. 1, open circles). These patients had an increased risk for the primary composite endpoint $(\mathrm{HR}=1.44, p=0.011)$ and for the composite renal endpoint ( $\mathrm{HR}=1.42, p=0.031)$ (Table 3). Losartan treatment reduced the risk of the primary composite endpoint and the renal composite endpoint in patients with LVH to that of patients without LVH and receiving placebo (Fig. 1, closed circles). Losartan reduced the risk of these endpoints in those patients without LVH (Fig. 1, closed triangles). Figure 2a,b show the KaplanMeier plots for the effect of losartan-based therapy vs placebo-based therapy on the primary composite endpoint and the renal composite endpoint.

\section{Interaction of treatment and $\mathrm{LVH}$ on $\mathrm{CV}$ outcomes}

The presence of LVH at baseline was associated with a $68 \%$ increased risk of $\mathrm{CV}$ events in patients with type 2 diabetes and nephropathy $(p=0.001$, Table 3 , Fig. 1 , open circles). Similarly to the reduction in risk for renal events, losartan-based therapy reduced the level of risk for $\mathrm{CV}$ events in patients with LVH (Fig. 1, closed circles) to the level observed in patients without LVH. By contrast, in subjects without $\mathrm{LVH}$, losartan did not change the risk for $\mathrm{CV}$ events (Fig. 1, closed triangles). The Kaplan-Meier plot for this parameter is shown in Fig. 2c.
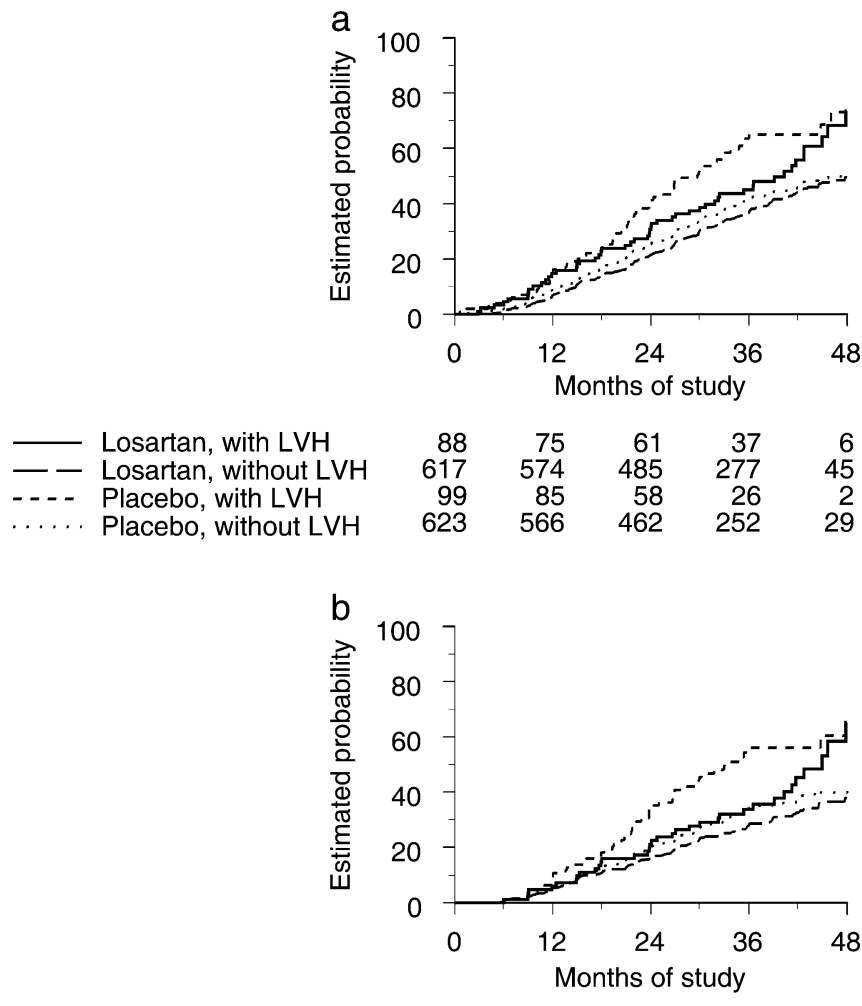

\begin{tabular}{|c|c|c|c|c|c|c|}
\hline $\begin{array}{l}-\overline{-} \\
---- \\
\ldots \ldots\end{array}$ & $\begin{array}{l}\text { Losartan, with LVH } \\
\text { Losartan, without LVH } \\
\text { Placebo, with LVH } \\
\text { Placebo, without LVH }\end{array}$ & $\begin{array}{r}88 \\
617 \\
99 \\
623\end{array}$ & $\begin{array}{r}75 \\
574 \\
85 \\
566\end{array}$ & $\begin{array}{r}61 \\
485 \\
58 \\
462\end{array}$ & $\begin{array}{r}37 \\
277 \\
26 \\
252\end{array}$ & $\begin{array}{r}6 \\
45 \\
2 \\
29\end{array}$ \\
\hline
\end{tabular}

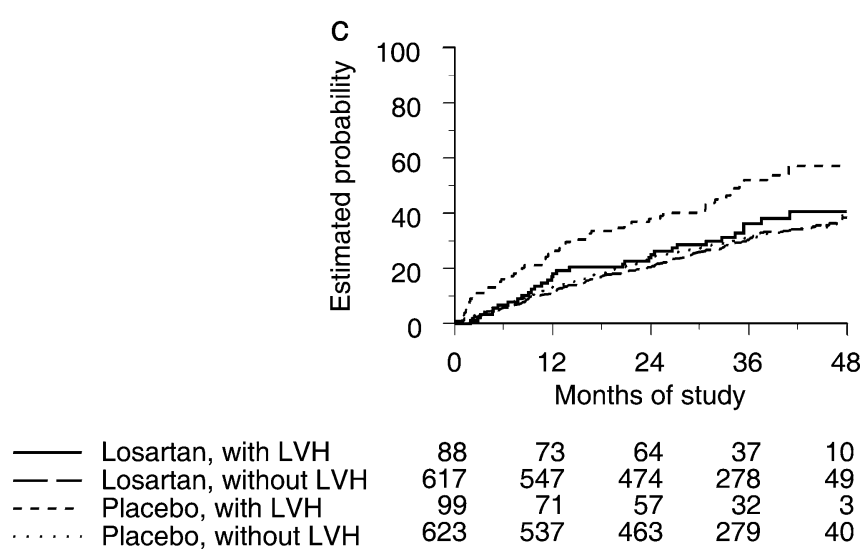

Fig. 2 Kaplan-Meier estimates of the influence of LVH and losartan-based therapy on a the primary composite endpoint of DSCR, ESRD or death; $\mathbf{b}$ the renal composite endpoint of DSCR/ ESRD; and (c) the CV morbidity and mortality composite endpoint

\section{Discussion}

This analysis shows that in patients with type 2 diabetes and nephropathy, the presence of LVH, based on ECG criteria, is a significant risk factor for the composite endpoint of DSCR, ESRD or death and the renal endpoint of DSCR/ESRD as well as for CV events. The importance of 
LVH as a determinant of both renal and CV outcomes has not been previously demonstrated in this population of proteinuric, diabetic subjects. Losartan was associated with a decrease in the electrocardiographic parameters of left ventricular size in the total RENAAL population, both in patients with or without LVH. This effect on LVH by an angiotensin receptor blocker appeared to be independent of $\mathrm{BP}$ reduction. Of particular relevance was the finding that losartan treatment reduced the risk of renal and CV events in patients with LVH (the highest risk group) to a level of risk similar to that observed in patients without LVH. These findings suggest that in patients with type 2 diabetes, nephropathy and $\mathrm{LVH}$, who are at increased CV risk, losartan-based therapy may provide cardioprotective effects in addition to the well-demonstrated renoprotective benefits. The proportion of subjects with overt, electrocardiographically diagnosed LVH in the total RENAAL cohort was only $12 \%$, and this may partly explain why there was no overall beneficial effect of losartan on CV outcomes, despite the significant effect in the patients with ECGLVH. No attempt was made to assess the effects of treatment on different categories of $\mathrm{CV}$ events in view of the total number of events in patients with LVH being only 82 .

The baseline incidence of LVH $(12 \%)$ in this population is less than that reported previously for diabetic patients $[25,26]$ and patients with chronic kidney disease $[11,27$, 28]. Possible reasons for this include the inclusion/exclusion criteria, which resulted in a low prevalence of $\mathrm{CV}$ disease [14] and the reasonably well-controlled BP in many subjects at baseline. Moreover, the presence of LVH was assessed using ECG criteria, while echocardiography has been used in other studies. A recent study has shown the prevalence of LVH diagnosed on ECG in a large population of type 2 diabetes to be $17 \%$ [29], similar to that observed in the present study. The data of the LIFE study showed that the same ECG criteria, as used in the RENAAL analysis, would identify approximately $70 \%$ of the LVH identified by echocardiography in hypertensive patients, thus underestimating the incidence of LVH [30]. Of interest is the fact that in the LIFE study, $65.9 \%$ of the subjects had an elevated Cornell product, $23.1 \%$ an elevated SokolowLyon voltage and $11.2 \%$ had an elevation of both values [20]. These figures are very similar to those presented in this study. The LIFE investigators also suggested that by using both criteria for the diagnosis of LVH they were able to select a study population enriched by a broader spectrum of risk factors. It has also been reported that echocardiography overestimated the left ventricular mass in patients on haemodialysis, presumably because of its dependence on ventricular volume, suggesting that prior studies using echocardiographic techniques may have overestimated the incidence of LVH [31]. Indeed, in a recent study it was shown that electrocardiographic diagnosis of LVH might be superior to echocardiography in diagnosing patients at high risk for ischaemic strokes [32].

Reduction of BP is associated with regression of $\mathrm{LVH}$ [33] and has been linked to a reduction in CV event rates in both hypertensive subjects and the general population [34-
36]. In the RENAAL study, losartan-based therapy significantly decreased both the Cornell product and Sokolow-Lyon voltage. In spite of the fact that the reduction in the systolic BP in subjects with LVH was greater in the placebo-based therapy, the reduction in LVH was more prominent in the losartan-treated group. Importantly, in patients with $\mathrm{LVH}$, the reduction in BP across the study was greater in the placebo-based therapy group than in the losartan-based therapy group, yet the effect on LVH was more prominent in the group receiving the angiotensin II antagonist. This would suggest that the regression of $\mathrm{LVH}$ associated with losartan-based therapy resulted from effects above and beyond BP reduction per se. This is consistent with data from LIFE, where losartan was found to have a greater effect in reducing Cornell product and Sokolow-Lyon voltage than atenolol despite similarly achieved BP levels in both the total cohort (15) and, of direct relevance to the current study, the diabetic subpopulation [37]. RENAAL is the first study to show that in patients with type 2 diabetes and clinical nephropathy, blockade of the angiotensin receptor has specific cardiac effects leading to regression of LVH above and beyond that which can be attributed to lowering BP.

An increased prevalence of LVH has been described in patients with diabetic nephropathy [38], including those with microalbuminuria [39]. Additional associations between the presence of $\mathrm{LVH}$ and the degree of proteinuria have also been reported [40, 41]. In this study, the presence of LVH at baseline significantly increased the risk for the primary composite endpoint and more importantly significantly increased the risk for the composite renal endpoint of DSCR or ESRD. Patients at greatest risk of renal outcomes were those who had LVH at baseline and were receiving placebo-based therapy. Patients with the lowest risk of renal endpoints were those who did not have LVH and were treated with losartan. Importantly, in patients with $\mathrm{LVH}$, losartan-based therapy reduced the risk of renal events to that seen in patients without LVH.

The current analysis demonstrates that $\mathrm{LVH}$, diagnosed on ECG, significantly increased the risk of developing a $\mathrm{CV}$ event in patients with diabetic nephropathy. Furthermore, losartan-based treatment of these high-risk patients reduced the level of risk for $\mathrm{CV}$ events to that of patients at much lower risk without LVH. While RENAAL did not demonstrate a clear cardioprotective role for losartan in the total cohort of patients with type 2 diabetes and nephropathy, these results do suggest that losartan could play a role in reducing $\mathrm{CV}$ events in diabetic subjects with $\mathrm{LVH}$, a setting of increased CV risk. These data are consistent with those from the LIFE study, where losartan conferred CV benefits in patients with LVH [37]. In particular, the findings from the LIFE diabetic sub-study have demonstrated the utility of angiotensin II receptor antagonism in conferring $\mathrm{CV}$ protection in the setting of concomitant LVH and diabetes [37].

A recent editorial, based on several studies predominantly in non-diabetic populations, has suggested that angiotensin receptor blockade may be associated with an 
increased risk of myocardial infarction [42]. However, in this analysis we were able to show the efficacy of losartan in reducing $\mathrm{CV}$ events in diabetic patients at very high risk. It is thus possible that the major beneficial effects of angiotensin receptor blockade are primarily seen in patients at very high $\mathrm{CV}$ risk such as those with diabetes, proteinuria and renal impairment.

These data lend further support to the concept of crosstalk between the renal and CV systems and further highlight that treatment of diabetic patients should not be designed to simply address either $\mathrm{CV}$ or renal disease progression, but should in fact encompass treatment that can reduce both outcomes. The number of patients found to have LVH at baseline, in this study, may be underestimated because ECG criteria were used to identify this phenomenon. Without the ability to use other techniques such as echocardiography or magnetic resonance imaging it is not possible to determine how many of these patients had anatomical LVH. However, the electrocardiographic expression of LVH may define a certain group of patients with a high risk for both cardiac disease and progression of renal disease.

In summary, LVH appears to confer an additional cardiorenal disadvantage on an already high-risk group of subjects, namely those with type II diabetes and nephropathy. Losartan-based therapy not only reduced LVH but also the risk conferred by $\mathrm{LVH}$ on $\mathrm{CV}$ and renal outcomes in this population.

Acknowledgements This study was presented in part at the 40th Annual Meeting of the European Association for the Study of Diabetes, Munich, Germany, September 2004.

Duality of interest

M. E. Cooper is the Chairman of the Publication Committee for the RENAAL study and a member of the RENAAL Steering Committee. In addition he has received honoraria from Merck and Amgen, and consulting fees from Sanofi-Synthelabo and Bristol-Myers Squibb.

K. McCarroll, S. Shahinfar and T. Dickson were employees of Merck and Co., Inc. and potentially own stock and/or hold stock options in the company.

B. M. Brenner is the Chairman of the RENAAL Steering Committee and a member of the Publication Committee for the RENAAL study. In addition, he has served on advisory panels for the following companies: Merck and Co., Inc., Amgen, Novartis and Genzyme. Further, he has received honoraria from the following companies: Merck and Co., Inc., Bristol-Myers Squibb, Amgen, Aventis and Genzyme.

D. de Zeeuw is a member of both the Steering and Publication Committees for the RENAAL study. In addition he has received consulting fees from Merck and Co., Inc., Bristol-Myers Squibb, Sanofi, Amgen, Actelion and Pfizer.

P. R. Kowey is a member of the RENAAL Data and Safety Monitoring Board. In addition, he has served on advisory panels for Merck and Co., Inc. His basic EP laboratory has received grant support from Merck. He has derived no personal benefit.

H-H. Parving is a member of both the Steering and Publication Committees for the RENAAL study. He is also the Chairman of the Steering Committee for the IRMA2 study. He has served on advisory panels for Merck and Co., Inc. Further, he has received honoraria and consultancy fees from the following companies: Merck and Co, Inc., Bristol-Myers Squibb and Sanofi.

G. Boner and R. S. Crow have no duality of interests.

\section{References}

1. Devereux RB, Alderman MH (1993) Role of preclinical cardiovascular disease in the evolution from risk factor exposure to development of morbid events. Circulation 88:1444-1455

2. Koren MJ, Devereux RB, Casale PN, Savage DD, Laragh JH (1991) Relation of left ventricular mass and geometry to morbidity and mortality in uncomplicated essential hypertension. Ann Intern Med 114:345-352

3. Levy D, Garrison RJ, Savage DD, Kannel WB, Castelli WP (1990) Prognostic implications of echocardiographically determined left ventricular mass in the Framingham Heart Study. N Engl J Med 322:1561-1566

4. Liao Y, Cooper RS, McGee DL, Mensah GA, Ghali JK (1995) The relative effects of left ventricular hypertrophy, coronary artery disease, and ventricular dysfunction on survival among black adults. JAMA 273:1592-1597

5. Vakili BA, Okin PM, Devereux RB (2001) Prognostic implications of left ventricular hypertrophy. Am Heart J 141:334 341

6. Hypertension in Diabetes Study (HDS) (1993) II. Increased risk of cardiovascular complications in hypertensive type 2 diabetic patients. J Hypertens 11:319-325

7. Butler R, MacDonald TM, Struthers AD, Morris AD (1998) The clinical implications of diabetic heart disease. Eur Heart J 19:1617-1627

8. Struthers AD, Morris AD (2002) Screening for and treating left-ventricular abnormalities in diabetes mellitus: a new way of reducing cardiac deaths. Lancet 359:1430-1432

9. Valensi P, Sachs RN, Lormeau B et al (1997) Silent myocardial ischaemia and left ventricle hypertrophy in diabetic patients. Diabetes Metab 23:409-416

10. Gerstein HC (2002) Epidemiologic analyses of risk factors, risk indicators, risk markers, and causal factors. The example of albuminuria and the risk of cardiovascular disease in diabetes. Endocrinol Metab Clin N Am 31:537-551

11. Foley RN, Parfrey PS, Sarnak MJ (1998) Epidemiology of cardiovascular disease in chronic renal disease. J Am Soc Nephrol 9:S16-S23

12. Liu JE, Robbins DC, Palmieri V et al (2003) Association of albuminuria with systolic and diastolic left ventricular dysfunction in type 2 diabetes: the Strong Heart Study. J Am Coll Cardiol 41:2022-2028

13. Levin A (2003) Clinical epidemiology of cardiovascular disease in chronic kidney disease prior to dialysis. Semin Dial 16:101-105

14. Brenner BM, Cooper ME, de Zeeuw D et al (2001) Effects of losartan on renal and cardiovascular outcomes in patients with type 2 diabetes and nephropathy. N Engl J Med 345:861-869

15. Dahlof B, Devereux R, Kjeldsen SE et al (2002) Cardiovascular morbidity and mortality in the Losartan Intervention For Endpoint reduction in hypertension study (LIFE): a randomised trial against atenolol. Lancet 359:995-1003

16. Brenner BM, Cooper ME, de Zeeuw D et al (2000) The losartan renal protection study-rationale, study design and baseline characteristics of RENAAL (Reduction of Endpoints in NIDDM with the Angiotensin II Antagonist Losartan). J Renin Angiotensin Aldosterone Syst 1:328-335

17. Dahlof B, Devereux R, de Faire U et al (1997) The Losartan Intervention For Endpoint reduction (LIFE) in Hypertension study: rationale, design, and methods. The LIFE Study Group. Am J Hypertens 10:705-713

18. Sokolow M, Lyon TP (1949) The ventricular complex in left ventricular hypertrophy as obtained by unipolar precordial and limb leads. Am Heart J 37:161-186

19. Okin PM, Roman MJ, Devereux RB, Kligfield P (1995) Electrocardiographic identification of increased left ventricular mass by simple voltage-duration products. J Am Coll Cardiol 25:417-423 
20. Okin PM, Devereux RB, Jern S et al (2000) Baseline characteristics in relation to electrocardiographic left ventricular hypertrophy in hypertensive patients: the Losartan intervention for endpoint reduction (LIFE) in hypertension study. The Life Study Investigators. Hypertension 36:766-773

21. Okin PM, Devereux RB, Jern S et al (2003) Regression of electrocardiographic left ventricular hypertrophy by losartan versus atenolol: The Losartan Intervention for Endpoint reduction in Hypertension (LIFE) Study. Circulation 108:684690

22. Okin PM, Jern S, Devereux RB, Kjeldsen SE, Dahlof B, Group FT (2000) Effect of obesity on electrocardiographic left ventricular hypertrophy in hypertensive patients: the losartan intervention for endpoint (LIFE) reduction in hypertension study. Hypertension 35:13-18

23. Prineas RJ, Crow RS, Blackburn H (1982) The Minnesota Code Manual of electrocardiographic findings. John Wright PSB, Boston, MA, pp 169-182

24. Molloy TJ, Okin PM, Devereux RB et al (1992) Electrocardiographic detection of left ventricular hypertrophy by the simple QRS voltage-duration product. J Am Coll Cardiol 20:11801186

25. Galderisi M, Anderson KM, Wilson PW, Levy D (1991) Echocardiographic evidence for the existence of a distinct diabetic cardiomyopathy (the Framingham Heart Study). Am J Cardiol 68:85-89

26. Devereux RB, Roman MJ, Liu JE et al (2000) Congestive heart failure despite normal left ventricular systolic function in a population-based sample: the Strong Heart Study. Am J Cardiol 86:1090-1096

27. Levin A, Singer J, Thompson CR, Ross H, Lewis M (1996) Prevalent left ventricular hypertrophy in the predialysis population: identifying opportunities for intervention. Am J Kidney Dis 27:347-354

28. London GM, Parfrey PS (1997) Cardiac disease in chronic uremia: pathogenesis. Adv Renal Replace Ther 4:194-211

29. Bruno G, Giunti S, Bargero G et al (2004) Sex-difference in prevalence of electrocardiographic left ventricular hypertrophy in Type 2 diabetes: the Casale Monferrato Study. Diabet Med 21:823-829

30. Devereux RB, Bella J, Boman K et al (2001) Echocardiographic left ventricular geometry in hypertensive patients with electrocardiographic left ventricular hypertrophy: The LIFE Study. Blood Press 10:74-82
31. Stewart GA, Foster J, Cowan M et al (1999) Echocardiography overestimates left ventricular mass in hemodialysis patients relative to magnetic resonance imaging. Kidney Int 56:22482253

32. Kohsaka S, Sciacca RR, Sugioka K et al (2005) Additional impact of electrocardiographic over echocardiographic diagnosis of left ventricular hypertrophy for predicting the risk of ischemic stroke. Am Heart J 149:181-186

33. Dahlof B, Pennert K, Hansson L (1992) Reversal of left ventricular hypertrophy in hypertensive patients. A metaanalysis of 109 treatment studies. Am J Hypertens 5:95-110

34. Yurenev AP, Dyakonova HG, Novikov ID et al (1992) Management of essential hypertension in patients with different degrees of left ventricular hypertrophy. Multicenter trial. Am J Hypertens 5:182S-189S

35. Muiesan ML, Salvetti M, Rizzoni D, Castellano M, Donato F, Agabiti-Rosei E (1995) Association of change in left ventricular mass with prognosis during long-term antihypertensive treatment. J Hypertens 13:1091-1095

36. Verdecchia P, Schillaci G, Borgioni C et al (1998) Prognostic significance of serial changes in left ventricular mass in essential hypertension. Circulation 97:48-54

37. Lindholm LH, Ibsen H, Dahlof B et al (2002) Cardiovascular morbidity and mortality in patients with diabetes in the Losartan Intervention For Endpoint reduction in hypertension study (LIFE): a randomised trial against atenolol. Lancet 359:10041010

38. Nielsen FS, Ali S, Rossing P et al (1997) Left ventricular hypertrophy in non-insulin-dependent diabetic patients with and without diabetic nephropathy. Diabet Med 14:538-546

39. Rutter MK, McComb JM, Forster J, Brady S, Marshall SM (2000) Increased left ventricular mass index and nocturnal systolic blood pressure in patients with Type 2 diabetes mellitus and microalbuminuria. Diabet Med 17:321-325

40. Gerstein HC, Mann JF, Pogue J et al (2000) Prevalence and determinants of microalbuminuria in high-risk diabetic and nondiabetic patients in the Heart Outcomes Prevention Evaluation Study. The HOPE Study Investigators. Diabetes Care 23(Suppl 2):B35-B39

41. Suzuki K, Kato K, Hanyu O, Nakagawa O, Aizawa Y (2001) Left ventricular mass index increases in proportion to the progression of diabetic nephropathy in Type 2 diabetic patients. Diabetes Res Clin Pract 54:173-180

42. Verma S, Strauss M (2004) Angiotensin receptor blockade and myocardial infarction. BMJ 329:1248-1249 